\title{
PSYCHOLOGICAL DISTRESS AND MENTAL WELL-BEING AMONG DOCTORS WORKING IN MAJOR TEACHING HOSPITALS OF PESHAWAR, PAKISTAN
}

\author{
Nazia Qureshi', Mubashar Shah ${ }^{2 凶}$, Naeema Arzeen ${ }^{3}$, Saima Arzeen'
}

\begin{abstract}
OBJECTIVES: To find out the relationship between psychological distress and mental well-being among doctors working in teaching hospitals of Peshawar, Pakistan; and explore the gender related differences on psychological distress and mental well-being among these doctors.
\end{abstract}

METHODS: This cross-sectional study was conducted on 270 doctors working in Khyber Teaching Hospital, (KTH), Lady Reading Hospital (LRH), and Hayatabad Medical Complex (HMC) Peshawar, Pakistan. Data was collected through convenient sampling technique. Two reliable and valid questionnaires, Kessler Psychological Distress Scale (KI0) and Warwick-Edinburgh Mental Well-Being Scale were used t measure psychological distress and mental wellbeing among doctors. Data analysis was done through SPSS-2 Iv.

RESULTS: Out of 270 doctors, I 54 (53. I\%) were male and I I 6 (40.0\%) were female doctors. Majority of doctors $(n=134 ; 46.2 \%)$ were from KTH, followed by HMC $(n=70 ; 24.1 \%)$ and LRH $(n=66 ; 22.8 \%)$. Overall descriptives indicates that data was normally distributed and alpha values of both scales were (K-10; $\alpha=0.78$ and MWB; $\alpha=0.86)$. Both psychological distress and mental well-being were negatively correlated with each other ($0.62 *$ * $\mathrm{p}<0.01$ ). Findings Also showed that female doctors had more Psychological distress than male doctors $(t=4.09)$.

CONCLUSION: Psychological distress and mental well-being among doctors working in major teaching hospitals of Peshawar Pakistan were negatively correlated with each other. Female doctors reported higher psychological distress as compared to male doctors.

KEYWORDS: Psychological Distress (MeSH); Mental Health (MeSH); Doctors (Non-MeSH).

THIS ARTICLE MAY BE CITED AS: Qureshi N, Shah M, Arzeen N, Arzeen S. Psychological distress and mental well-being among doctors working in major teaching hospitals of Peshawar, Pakistan. Khyber Med Univ J 2021;I3(I):40-2. DOI: https://doi.org/l0.35845/kmuj.202I.20I4I.

\section{INTRODUCTION}

$\mathrm{D}$ octors play a key role in taking care of the patients and usually go through multitasking while treating them. This may lead to psychological distress and overburden that may affect their overall well-being. The practice of medicine is unique and challenging than any other profession in the world. It is associated not only with a great degree of both personal and professional satisfaction, but also with a high level of occupational stress and burnout. Previous studies have shown across the world that health-care professionals, especially resident doctors/trainees and faculty members, are prone to developing mental health problems such as depression, anxiety, and substance abuse. ${ }^{1.2}$ Psychological distress can be due to external (situational) or internal (feeling) facts for long time or for short time period distress takes placed. In interpersonal view, psychological distress is maladaptive behavior that is observed. Mental well-being is the individuals' 'mental state' how they feel and how well they can cope with day-to-day life. ${ }^{3}$

It is now generally accepted that prolonged or intense stress can have a negative impact on an individual's mental
I: Department of Psychology, University of Peshawar, Peshawar, Pakistan.

2: Department of Psychiatry, Combined Military Hospital, Peshawar, Pakistan.

Emailه: mubashirsha_dr@yahoo.com Cell \# +92-321-5286308

3: University of Modern Languages Islamabad, Pakistan.

Date Submitted: February 28, 2020

Date Revised: January 27, 2021

Date Accepted: January 29, 2021

and physical health. ${ }^{4.5}$ The stress experienced by different occupation types and job roles has been discussed in many papers with a number of different occupations being described as experiencing above average levels of stress, for example, healthcare, nurses and social workers, and the ambulance service. There are a number of work related stressors which have been linked to an increased likelihood of individual experiencing negative stress outcomes. In Spain one study was conducted to investigate the psychological well-being among doctors and nurses. Findings indicated that those doctors who experienced higher work family related conflicts and emotional demands mostly reported lower levels of psychological well-being. They experienced greater anxiety and depression because of emotional burden. ${ }^{6}$

Another study included fifty health professionals, including doctors, paramedical and nursing staffs from different multi-specialty hospitals in Kolkata were assessed using different questioners, majority of the subjects had evidence of psychological distress. Stress level was present in varying degree among all professionals, while nurses and technicians had stress level at severe level. ${ }^{7}$

Medical profession is very important in all types of cultures and the responsibilities of doctors' are too much. In Pakistan, A study showed that mild to moderate anxiety and depression was present in $34 \%$ \& $24.8 \%$ respectively among doctors working in a hospital of Lahore. ${ }^{8}$ However, there are no such studies on 
psychological distress and mental wellbeing among doctors working in teaching hospitals and explore the gender related differences among these doctors. In our society, there are some specific roles for men and women so there is a need to explored gender related differences on distress and well-being among doctors. This study was planned to find out the relationship between psychological distress and mental well-being among doctors working in teaching hospitals of Peshawar, Pakistan; and explore the gender related differences on psychological distress and mental wellbeing among these doctors.

\section{METHODS}

This cross-sectional study was conducted on $\mathbf{2 7 0}$ doctors working in Khyber Teaching Hospital, (KTH), Lady Reading Hospital (LRH), and Hayatabad Medical Complex (HMC) Peshawar, Pakistan. Data was collected through convenient sampling technique.

After taking approval from ethical review board, permission for conducting research was taken from higher authorities of the hospitals.

Covenient sampling technique was used for collection of sample. Informed consent was taken from all the participants of the study and only doctors consenting for participation in research were enrolled in the study. Demographic sheet along with two standardized scales Kessler Psychological Distress Scale $(\mathrm{K}-\mathrm{IO})^{9}$ and Warwick-Edinburgh Mental Well-Being Scale (WMWBS) ${ }^{10}$ were administered to each participant. For the analysis SPSS2 IV was used and descriptive statitics ( $M, S D$, Cronbach alpha, Skewness, and Kurtosis), Pearson product moment correlation (for relationship between psychological distress and mental wellbeing), and t-test (male and female differences) were computed.

\section{RESULTS}

Out of 270 doctors, 154 (53. I\%) were male and II6 (40.0\%) were female doctors. Majority of doctors $(n=134$; $46.2 \%$ ) were from $\mathrm{KTH}$, followed by HMC $(n=70 ; 24.1 \%)$ and LRH $(n=66$; $22.8 \%)$.

Overall descriptives indicate that data was normally distributed and alpha values of both scales were $\mathrm{K}-\mathrm{IO}$; $\alpha=0.78$ and $M W B ; \alpha=0.86$.

Relationship between psychological distress and mental well-being was analysed and both psychological distress and mental well-being scales were negatively correlated with each other $(r=-0.62 * *<<0.01)$.

Gender-based comparison of psychological distress and mental wellbeing among doctors significant mean difference between men and women on psychological distress; but is nonsignificant mean difference on mental well-being (Table I).

\section{DISCUSSION}

This research examined the relationship of psychological distress and mental well-being among doctors. Table I indicated the demographic details of study which showed all the hospitals details. Both scales (K-IO and MWB) were reliable instruments according to the criteria which was above 0.7." Findings showed the negative correlation between psychological distress and mental well-being $(-0.62 * *)$ that was the assumption of the study. The findings of the study were in line with previous study which investigated stress and psychological well-being among health care professionals. Results indicated that there was significant negative correlation between perceived stress and psychological well-being among doctors (-.288***, $\mathrm{p}<0.0 \mathrm{I})$. $^{12}$

Another study reported that $30.1 \%$ doctors were found to have depression and $16.7 \%$ of participants reported suicidal ideations. About two-thirds of the sample experienced moderate level of stress $(67.2 \%)$ and another $13 \%$ of participants reported high level of stress. More than $90 \%$ of the participants reported some level of burnout. Various factors associated with such results that were lower indulgence in recreational activities, experiencing verbal or physical abuse in the hand of patients/caregivers, feelings that seniors do not show empathy toward patients, and seniors do not show empathy toward them. ${ }^{13}$

Results indicated that there were significant mean differences on psychological distress among male and female doctors (Table I) but nonsignificant mean differences on mental well-being. Another study's findings showed that health service workers such as managers, doctors, nurses and professions allied to medicine $(26.8 \%)$ had minor psychiatric disorder as compared to general population (17.8\%). Moreover findings also indicated gender differences that are inline with the current study's assumption that female doctors showed a much higher prevalence than their male colleagues. ${ }^{14}$ In this context both of the assumptions of this study suggest that medical professionals in teaching hospitals of Peshawar Pakistan are at risk and especially female doctors having higher level of psychological distress than their male colleagues.

Medical profession is considered the signicant humanitarian profession throughout world. No society and its members deny the importance of this profession; this study was a little effort to highlighted the significance of this profession in Peshawar city of Khyber Pakhtunkhwa, Pakistan. In our local context the need of this profession is of greater concern because of terrorist related activities. The findings of this study may be applied in various areas of mental health professions (e.g., clinical, social, and positive). On the basis of findings of this study various interventions based strategies can initiated for the members who are

TABLE I: PSYCHOLOGICAL DISTRESS AND MENTAL WELL-BEING AMONG MALE AND FEMALE DOCTORS (N=270)

\begin{tabular}{|c|c|c|c|c|c|c|c|c|c|}
\hline \multirow{2}{*}{ Scales } & \multicolumn{2}{|c|}{$\begin{array}{c}\text { Men } \\
(\mathrm{n}=154)\end{array}$} & \multicolumn{2}{|c|}{$\begin{array}{l}\text { Women } \\
(\mathrm{n}=1 \mathrm{I})\end{array}$} & \multirow{2}{*}{$t(268)$} & \multirow{2}{*}{$P$} & \multicolumn{2}{|c|}{$\mathrm{Cl} 95 \%$} & \multirow{2}{*}{ Cohen's d } \\
\hline & $M$ & SD & $M$ & SD & & & LL & UL & \\
\hline$K-10$ & 32.29 & 7.60 & 46.54 & 5.73 & 4.09 & 0.05 & -6.08 & -.15 & .33 \\
\hline MWB & 149.8 & 29.75 & 148.3 & 29.7 & .25 & .80 & -10.53 & 10.60 & .20 \\
\hline
\end{tabular}


engaged in this profession. They are considered the main pillars for providing services to the needy ones if they develop better coping patterns they can deal with clients in a better way.

\section{LIMITATIONS}

This study was conducted on doctors working in three major teaching hospitals of Peshawar, Pakistan and the results cannot be generalized to other hospitals and cities of Pakistan.

\section{CONCLUSION}

This study cocluded that both constructs of the study psychological distress and mental well-being among doctors working in major teaching hospitals of Peshawar Pakistan were negatively correlated with each other. Due to overburdening doctors faces more psychological distress and due to these stresses their mental well-being is badly affected. Also female doctors reported higher psychological distress as compared to male doctors. This study will help in future studies to look for this humanitarian profession (doctors) and various related issues which impact on doctors' mental health.

\section{REFERENCES}

I. Mavroforou A, Giannoukas A, Michalodimitrakis E. Alcohol and drug abuse among doctors. Med Law 2006;25:6 I I 25.

2. Shanafelt TD, Boone $S$, Tan $L$, Dyrbye LN, Sotile W, Satele D, et al. Burnout and satisfaction with work- life balance among US physicians relative to the general US population. Arch Intern Med 2012 Oct 8;172 (I8):1377-85. DOI: I0.100I/ archinternmed.2012.3199.

3. World Health Organization [WHO]. Investing in Mental Health. Geneva, Switzerland; 2003.

4. Health and Safety Executive. Tackling Work-related Stress, HSE Books, London; $200 \mathrm{I}$.

5. Cooper CL, Dewe PJ, O'Driscoll MP. Organizational stress: A review and critique of theory, research and applications. Sage Publications, CA: 2001 .

6. Burke RJ, Moodie S, Dolan SL, Fikesbaum L. Job demands, social support, work-satisfaction and psychological well-being among nurses in Spain. Esade Working Paper 20I2;233:60-2. DOI: 10.2139/ssrn.2117051.

7. Madhuchandra MK, Srimathi NL. Psychological Well-being among Doctors and Nurses: A Comparative Study. Int J Indian Psychol 2016;3(4):203-10.

8. Atif K, Khan HU, Ullah MZ, Shah FS, Latif A. Prevalence of anxiety and depression among doctors; the unscreened and undiagnosed clientele in Lahore, Pakistan. Pak J Med Sci 2016 Mar-Apr;32(2):294-8. DOI: 10.12669/pjms.322.8731.

9. Kessler RC, Andrews G, Colpe LJ, Hiripi E, Mroczek DK, Normand
SLT, et al. Short screening scales to monitor population prevalence and trends in non-specific psychological distress. Psychol Med 2002; 32(6): 959-6. DOI: 10.1017/s0033291702 006074.

I0. Tennant R, Hiller L, Fishwick R, Platt S, Joseph S, Weich S, et al. The Warwick-Edinburgh Mental Wellbeing Scale (WEMWBS): development and UK validation. Health Qual Life Outcomes 2007;5:63. DOI: I0. I I86/ |477-7525-5-63.

II. Nunnally JC, Bernstein IH. The assessment of reliability. Psychometric Theory New York: McGraw Hill, $3^{\text {rd }}$ ed, 2003.

12. Nazir N, Hussain A, Tanveer F, Subhan Ullah, Khokar M, Sabri AA. Correlation of perceived stress and psychological well-being among doctors serving at various government and private hospitals of Faisalabad. Rawal Med J 2020; 45(4):886-9.

13. Grover S, Sahoo S, Bhalla A, Avasthi A. Psychological problems and burnout among medical professionals of a tertiary care hospital of North India: A cross-sectional study. Indian J Psychiatry 2018; 60(2): 175-88. DOI: 10.4103/psychiatry. IndianJPsychiatry_254_17

14. Wall DT, Bolden R, Borrill CS, West AM. Psychiatric disorder in NHS trust staff: Occupational and gender differences. Br J Psychiatry 1998; I 7 I (6): 519-23. DOI: I0.1 192/bjp. I7I.6.519.

\section{AUTHOR'S CONTRIBUTION}

Following authors have made substantial contributions to the manuscript as under:

NQ: Concept and study design, acquisition of data, drafting the manuscript, approval of the final version to be published.

MS: Analysis and interpretation of data, drafting the manuscript, approval of the final version to be published.

NA: Acquisition, analysis and interpretation of data, critical review, approval of the final version to be published.

SA: Analysis and interpretation of data, drafting the manuscript, approval of the final version to be published.

Authors agree to be accountable for all aspects of the work in ensuring that questions related to the accuracy or integrity of any part of the work are appropriately investigated and resolved.

\section{\begin{tabular}{|c|}
\hline CONFLICT OF INTEREST \\
Authors declared no conflict of interest \\
GRANT SUPPORT AND FINANCIAL DISCLOSURE \\
Authors have declared no specific grant for this research from any \\
funding agency in the public, commercial or not-for-profit sectors
\end{tabular}}

\section{DATA SHARING STATEMENT}

The data that support the findings of this study are available from the corresponding author upon reasonable request.

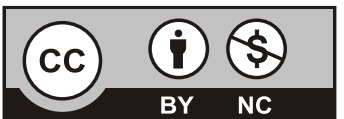

This is an Open Access article distributed under the terms of the Creative Commons Attribution-Non Commercial 2.0 Generic License. 